\title{
TEM Study of Precipitation Sequences in Haynes 282 Ni Superalloy
}

\author{
A. Alexandratou ${ }^{1}$, S. Deligiannis ${ }^{1}$, D. Liolios ${ }^{1}$ and P. Tsakiridis ${ }^{1}$
}

1. Lab. of Physical Metallurgy, School of Mining and Metallurgical Engineering, National Technical University of Athens, Athens, Greece

The ever-increasing demand for higher operating temperatures and pressures in critical gas turbine applications, leading to improved efficiency and reduced greenhouse gas emissions, necessitates the use of advanced superalloys with exceptional high temperature performance. Haynes 282 is a recently developed wrought, $\gamma^{\prime}$ strengthened Ni-based superalloy, suitable for fabrication of hot section components in aircraft and land based gas turbines. The alloy is notable for its unique combination of high temperature creep and yield strength, thermal stability and good fabricability. A key attribute of Haynes 282 that influences mechanical properties at elevated temperatures is its microstructural stability upon long-term thermal exposure, an issue that has not been adequately addressed to date $[1,2]$. The present TEM study will provide a thorough insight into the area of microstructural evolution of Haynes 282 following variable heat treatments. The nominal chemical composition (wt. \%) of the studied material is $20 \mathrm{Cr}, 10 \mathrm{Co}, 8.5 \mathrm{Mo}, 2.1 \mathrm{Ti}, 1.5 \mathrm{Al}, 1.5 \mathrm{Fe}, 0.3 \mathrm{Mn}, 0.15 \mathrm{Si}, 0.06 \mathrm{C}, 0.005 \mathrm{~B}$ and balance $\mathrm{Ni}$ [1].

Based on this composition, the as-received (AR) wrought alloy (Fig.1), was subjected to the standard full heat treatment: a solution-annealing treatment (ST) at $1140^{\circ} \mathrm{C}$ for $2 \mathrm{~h}$, followed by water quenching and then a two-step precipitation treatment, at $1010^{\circ} \mathrm{C}$ for $2 \mathrm{~h}$ (first ageing, FA) and at $788^{\circ} \mathrm{C}$ for $8 \mathrm{~h}$ (second ageing, SA), both followed by air-cooling [2]. The first stage of ageing, which is slightly above the $\gamma^{\prime}$ solvus temperature $\left(997^{\circ} \mathrm{C}\right)$ precipitates discrete grain boundary carbides $\left(\mathrm{M}_{6} \mathrm{C}, \mathrm{M}_{23} \mathrm{C}_{6}\right)$, while the second results in the formation of spherical and finely dispersed $\gamma^{\prime}$ phase, with an average size of $20 \mathrm{~nm}$. Moreover, in order to evaluate the thermal stability of Haynes 282, the second step of age hardening was conducted with a longer holding time (1000h).

The present study highlighted, for the first time, the effect of increasing holding time at the second stage of precipitation treatment on the microstructural evolution of Haynes 282. Following 1000h exposure at $788^{\circ} \mathrm{C}, \gamma^{\prime}$ precipitates were observed to coarsen, having an average size of $100 \mathrm{~nm}$, in comparison to 40 $\mathrm{nm}$ and $20 \mathrm{~nm}$ respectively, in the $\mathrm{AR}$ and $\mathrm{ST}+\mathrm{FA}+\mathrm{SA}_{8}$ conditions. $\gamma^{\prime}$ phase nanoparticles precipitated out during the second ageing in a spherical morphology, while extended distributions were observed with increasing ageing time (Figs. 2, 3 and 5). Two types of grain boundary precipitates were identified in all three conditions of the studied superalloy (Figs. 2 and 4). SEM and TEM examination coupled with EDS spot-microanalyses and XRD analysis (Fig. 6), indicated the extended intergranular precipitation of $\mathrm{Cr}$-based $\mathrm{M}_{23} \mathrm{C}_{6}$, in addition to Mo-based $\mathrm{M}_{6} \mathrm{C}$. Increasing ageing time to $1000 \mathrm{~h}$ at $788^{\circ} \mathrm{C}$ resulted in carbide coarsening, as well as, intragranular precipitation of sub-micron $\mathrm{M}_{23} \mathrm{C}_{6}$, adjacent to $\gamma^{\prime}$ phase (Figs. 4, 5). Finally, primary cubic Ti rich nitrides (MN) and blocky Ti, Mo rich carbides (MC) were found scattered throughout the $\gamma$ phase in all three samples (Figs. 1, 4), while there was no evidence of TCP formation following the $1000 \mathrm{~h}$ thermal exposure.

References:

[1] L. M. Pike, Proceedings of the $7^{\text {th }}$ Int. Symposium on Superalloy 718 and Derivatives (2010), p. 645. [2] C. Joseph, C. Persson, M. Hörnqvist Colliander, Mater. Sci. Eng. A, 679 (2017), p. 520. 


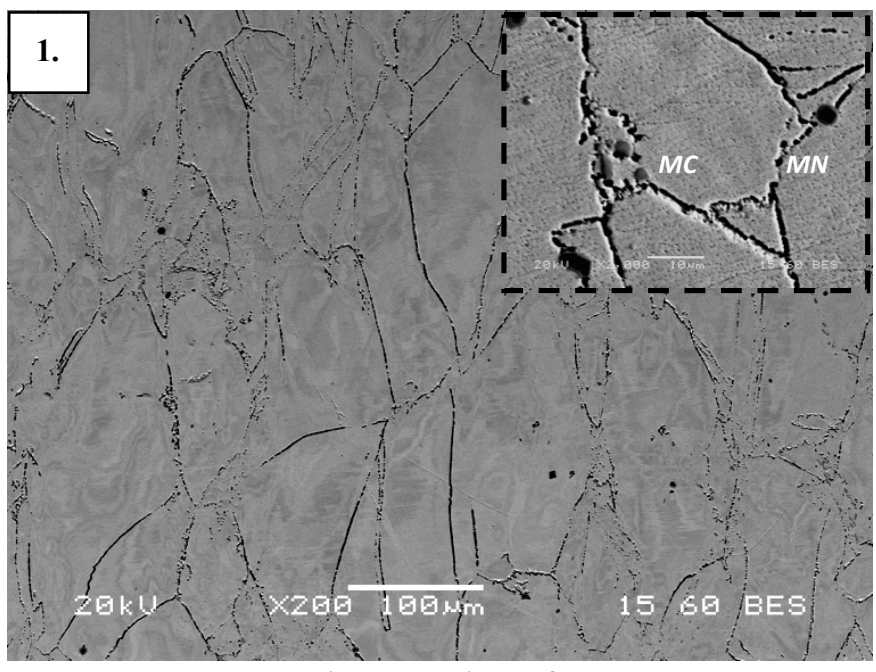

Figure 1. BES micrographs of AR Haynes 282, outlining the precipitation of discrete Ti-based MC and $\mathrm{MN}$ in the $\gamma$ phase (matrix).

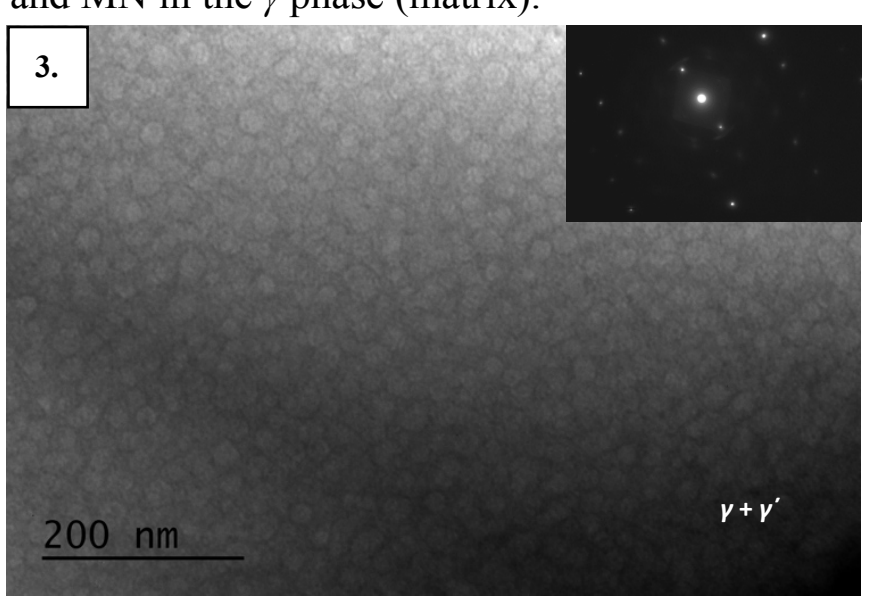

Figure 3. BF TEM micrograph of the $\mathrm{ST}+\mathrm{FA}+\mathrm{SA}_{8}$ Haynes 282, showing the distribution of $\gamma^{\prime}$ phase $(\approx 20 \mathrm{~nm})$ within the matrix.

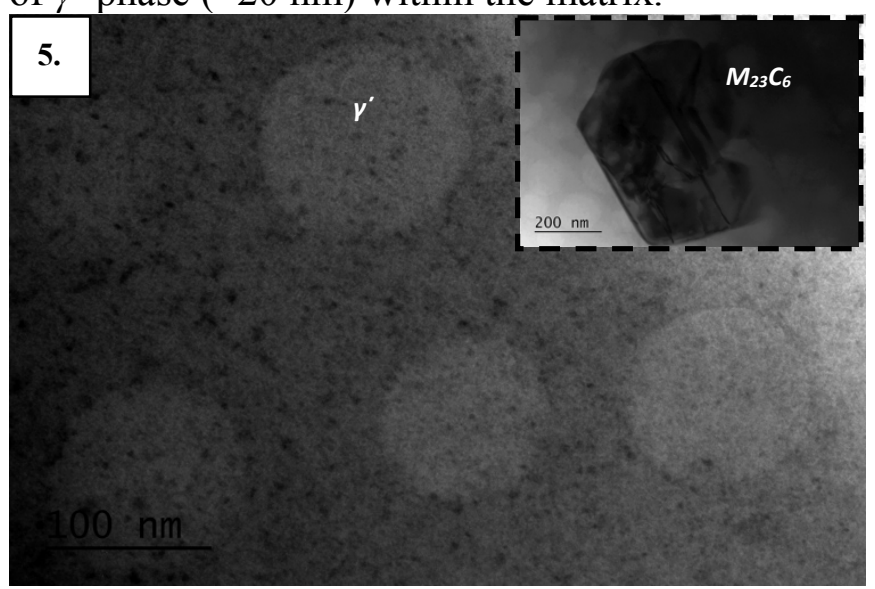

Figure 5. BF TEM micrographs showing coarsened $\gamma^{\prime}$ phase $(\approx 100 \mathrm{~nm})$ and a Cr-rich $\mathrm{M}_{23} \mathrm{C}_{6}$ precipitation in $\mathrm{ST}+\mathrm{FA}+\mathrm{SA}_{1000}$ Haynes 282.

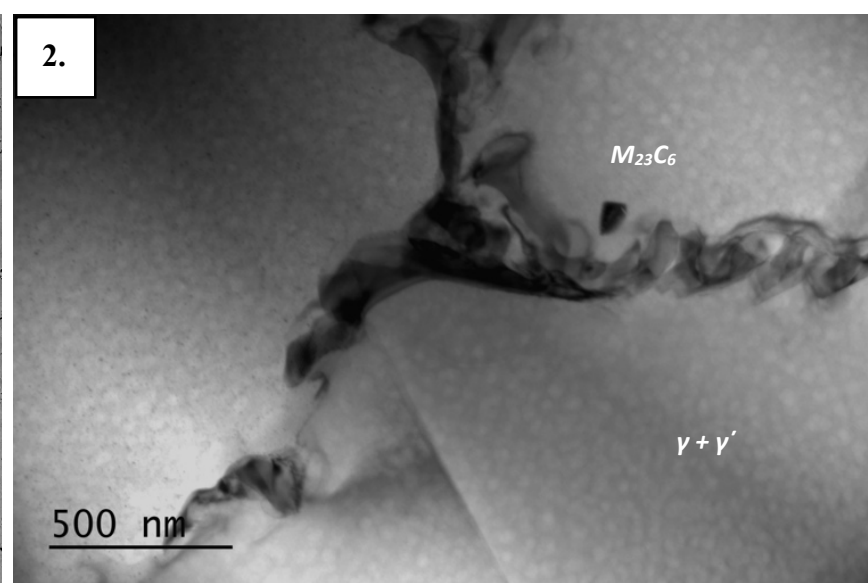

Figure 2. BF TEM micrograph of the AR Haynes 282, showing $\mathrm{Cr}$-based $\mathrm{M}_{23} \mathrm{C}_{6}$ along the grain boundary triple junctions and the fine dispersion of $\gamma^{\prime}$ phase $(\approx 40 \mathrm{~nm})$ within the matrix.

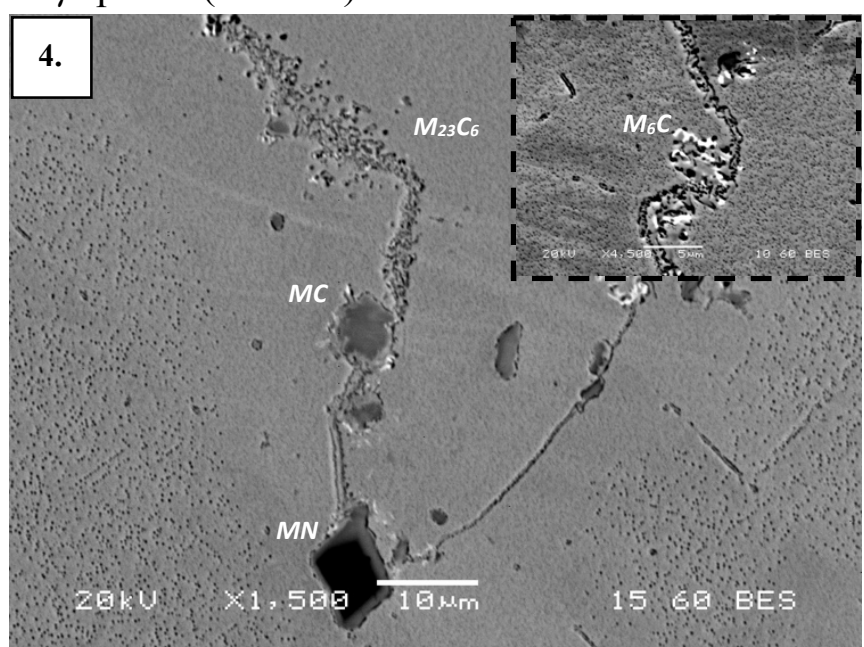

Figure 4. BES micrographs of the $\mathrm{ST}+\mathrm{FA}+\mathrm{SA}_{1000}$ Haynes 282, outlining the precipitation of Ti rich $\mathrm{MC}$ and $\mathrm{MN}$ and the presence of intergranular $\mathrm{Cr}$ based $\mathrm{M}_{23} \mathrm{C}_{6}$ and Mo-based $\mathrm{M}_{6} \mathrm{C}$ (light contrast precipitates).

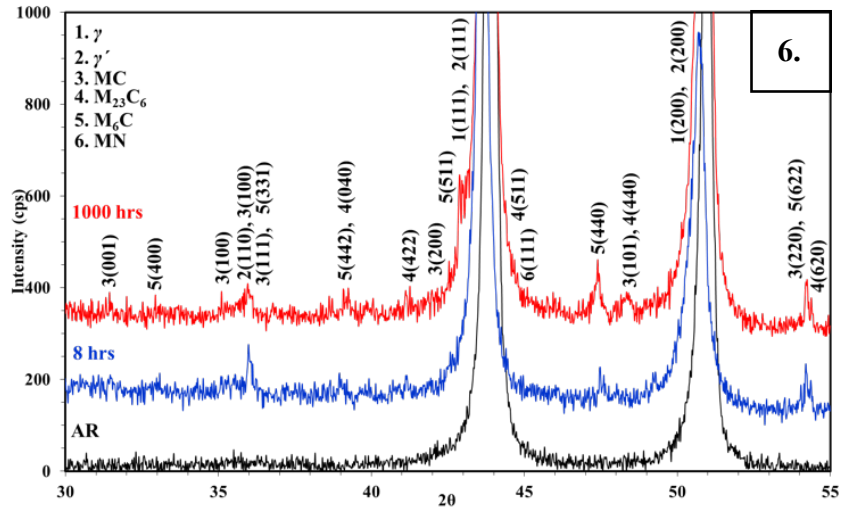

Figure 6. $\mathrm{XRD}$ traces of $\mathrm{AR}, \mathrm{ST}+\mathrm{FA}+\mathrm{SA}_{8}$ and ST+FA+SA1000 Haynes 282. 